\title{
Hypertestosteronemia and primary infertility from a mediastinal extragonadal germ cell tumor
}

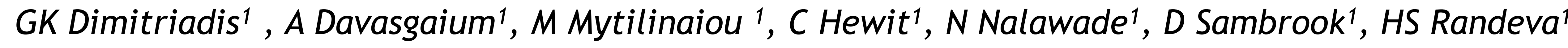

WISDEM Centre - ARDEN NET COE and the Human Metabolism Research Unit (HMRU), University Hospitals Coventry and Warwickshire (UHCW) NHS Trust.

\section{Introduction}

Extragonadal germ cell tumors (EGCTs) are tumors of gonadal origin representing $<5 \%$ of germ cell malignancies that form outside gonads. These are typically found in the mediastinum, retroperitoneum or pineal gland.

\section{Clinical Presentation}

A 26-year-old male presented to the Reproductive Endocrinology outpatient clinic, in January 2016 with a two year history of infertility. He had known hypertrophic cardiomyopathy due to MYH7 sarcomere mutation, treated with implantable cardioverterdefibrilator while his partner was healthy. Initial investigations performed by their GP, showed hypertestosteronemia $(52.9 \mathrm{nmol} / \mathrm{L}$, normal range 9.0$26.0 \mathrm{nmol} / \mathrm{L}$ ) and azoospermia ( 0 sperm per $20 \mathrm{ml}$ of ejaculate).

During consultation, he reported hoarseness of voice, hypersexuality, and increased hair distribution on torso and extremities over the past 3 years. He denied having used anabolic steroids or any supplements and was only on amiodarone to ameliorate arrhythmias from his hypertrophic cardiomyopathy. On examination he had normal stature, was hirsute with bilaterally small testes ( $<10 \mathrm{cc}$ each) but no evidence of any masses during palpation. A testicular/scrotal U/S was unremarkable. Subsequent investigations revealed consistently elevated testosterone $(52.9 \mathrm{nmol} / \mathrm{L})$, B-hCG $(900 \mathrm{lU} / \mathrm{L}$, normal range: $<1 \mathrm{IU} / \mathrm{L})$, oestradiol $(738 \mathrm{pmol} / \mathrm{L}$, normal range: 36.7-147pmol/L) and suppressed FSH and LH $(<1 \mathrm{IU} / \mathrm{L}$, normal FSH: 2-9IU/L, LH: 2-12IU/L) while remaining tests were normal. The provisional diagnosis of an EGCT was suspected and whole body $C T$ revealed a $7 \times 6 \times 5 \mathrm{~cm}$ mass of the anterior mediastinum (Figure 1) without further disease dissemination. Due to his hypertrophic cardiomyopathy and reduced ejection fraction (EF: $35 \%$ ) he was not eligible for neo-adjuvant treatment with bleomycin-etoposide-cisplatin (BEP) ${ }^{1}$, in view of the increased risk for cardiotoxicity ${ }^{2}$ and was instead referred for surgery. Immediately following excision of the mass, his testosterone dropped to undetectable levels $(1.0 \mathrm{nmol} / \mathrm{L})$ (Figure 2) confirming that B-hCG hypersecretion by the tumor was driving hypertestosteronemia. Post-surgically, considering his hypertrophic cardiomyopathy, he was offered one high dose adjuvant carboplatin cycle (6AUC). He was not referred for surgical sperm extraction before chemotherapy due to the low risk of gonadal toxicity from one carboplatin cycle $^{3}$. At last follow-up, his testosterone was normal $(18.7 \mathrm{nmol} / \mathrm{L})$ without evidence of disease recurrence and the couple was referred for microsurgical sperm retrieval followed by IVF with ICSI ${ }^{4}$.

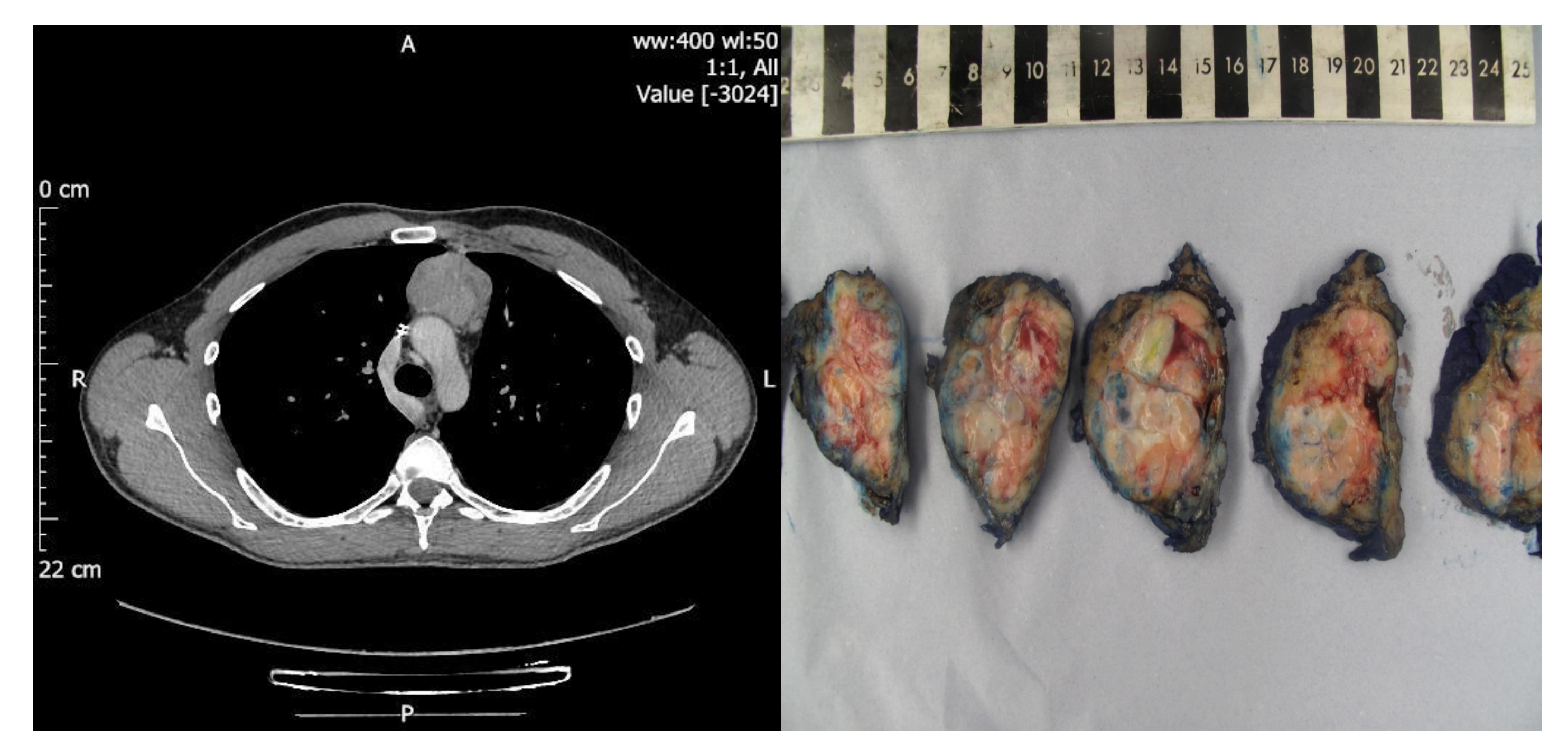

Figure 1: Whole body contrast enhanced computerized tomography reveals a $7 \times 6 \times 5 \mathrm{~cm}$ mass of the anterior mediastinum. Macroscopic image of the excised tumour.
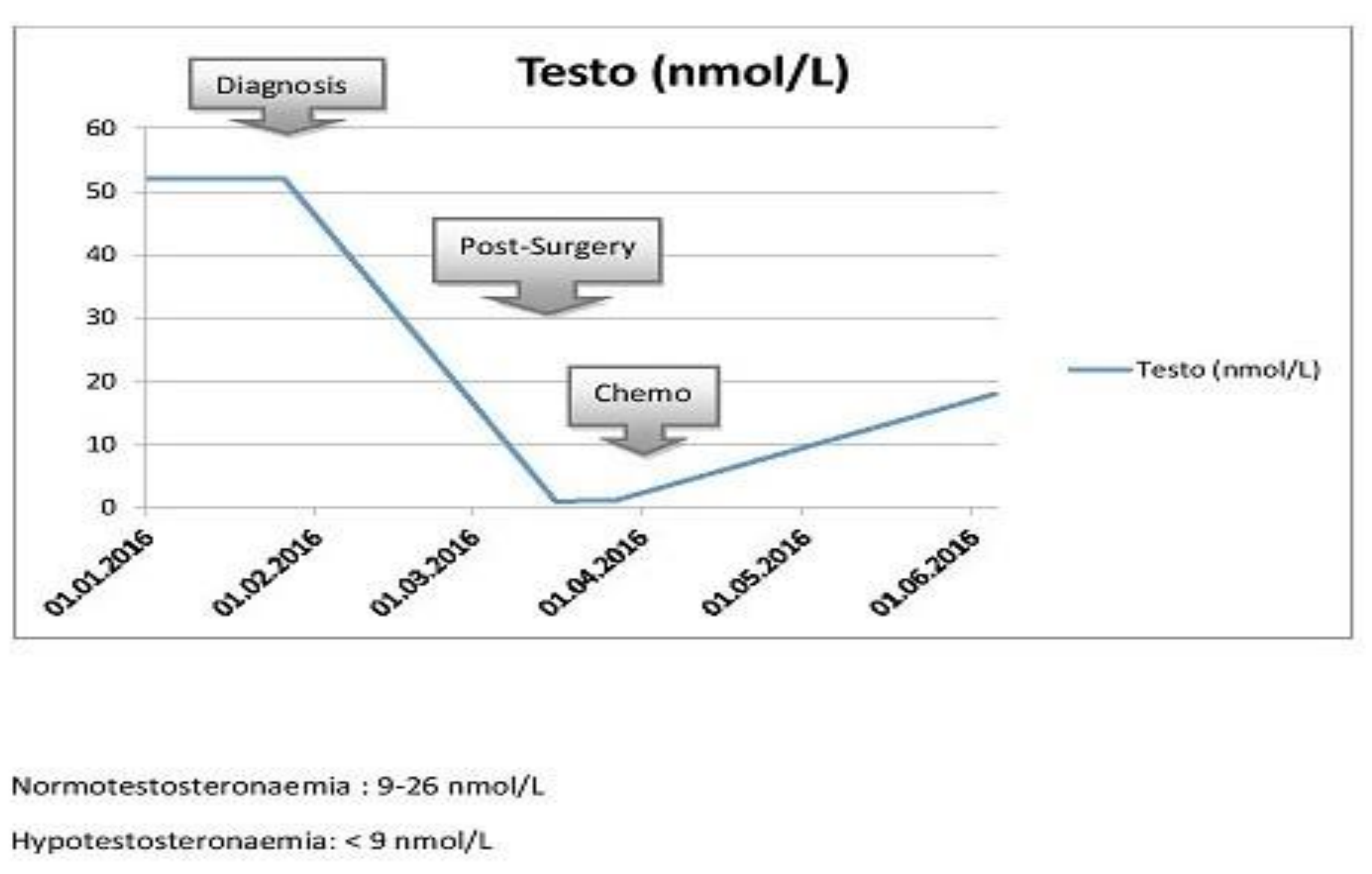

Hypertestosterona

Figure 2: Testosterone levels in relation to interventions throughout disease clinical course

\section{Conclusions}

EGCT treatment and prognosis depends on factors like cancer type, tumor location, and tumor size. Treatment of choice remains combined neo-adjuvant chemotherapy followed by surgery. Hypertestosteronemia is defined by abnormally high levels of testosterone, characterized by precocious puberty, increased muscle mass, acne vulgaris and polycythemia. In adult males, hypertestosteronemia and azoospermia can be secondary to congenital adrenal hyperplasia, androgen abuse or testicular or adrenal tumors particularly when testosterone levels exceed normal limit by > 50\%. Rarely, hypertestosteronemia and azoospermia are associated with an EGCT. Increased B-hCG is associated with suppression of gonadotropin response to gonadotropin-releasing hormone in the pituitary, resulting in inhibition of $\mathrm{LH}$ and FSH. Also, B-hCG secreted by EGCTs may stimulate androgen production by the testes. Hypertestosteronemia can therefore appear as a biochemical finding not to be ignored. Managing physicians should be careful not to erroneously interpret hypertestosteronemia which can easily be attributed to lifestyle factors, as in rare cases such as this, may lead to infertility but more importantly to increased morbidity and mortality.

\section{References}

${ }^{1}$ Riggs SB, Burgess EF, Gaston KE, Merwarth CA, Raghavan D. Postchemotherap Surgery for Germ Cell Tumors-What Have We Learned in 35 Years? The Oncologist 2014;19:498-506.

Herrmann J, Yang EH, lliescuCA et al. Vascular toxicities of cancer therapies: The old and the new -an evolving avenue. Circulation. 2016 Mar 29;133(13):1272-89. ${ }^{3}$ Ghezzi M, Berretta M, Bottacin A et al. Impact of BEP or Carboplatin chemotherapy on testicular function and sperm nucleus of subjects with testicular germ cell tumor. Front. Pharmacol. 7:122. doi: 10.3389/fphar.2016.00122.

${ }^{4}$ Cetinkaya M, Onem K, Zorba OU, Ozkara H, Alici B. Evaluation of Microdissection Testicular Sperm Extraction Results in Patients with Non-Obstructive Azoospermia Independent Predictive Factors and Best Cutoff Values for Sperm Retrieval. Uro J. 2015 Dec 23;12(6):2436-43. 